\title{
Scaphanocephalus-associated dermatitis as the basis for black spot disease in Acanthuridae of St. Kitts, West Indies
}

\author{
Michelle M. Dennis ${ }^{1, *}$, Adrien Izquierdo ${ }^{1}$, Anne Conan ${ }^{1}$, Kelsey Johnson ${ }^{1}$, \\ Solenne Giardi ${ }^{1,2}$, Paul Frye ${ }^{1}$, Mark A. Freeman ${ }^{1}$
}

${ }^{1}$ Center for Conservation Medicine and Ecosystem Health, Ross University School of Veterinary Medicine, St. Kitts, West Indies ${ }^{2}$ Department of Sciences and Technology, University of Bordeaux, Bordeaux, France

\begin{abstract}
Acanthurus spp. of St. Kitts and other Caribbean islands, including ocean surgeonfish $A$. bahianus, doctorfish $A$. chirurgus, and blue tang $A$. coeruleus, frequently show multifocal cutaneous pigmentation. Initial reports from the Leeward Antilles raised suspicion of a parasitic etiology. The aim of this study was to quantify the prevalence of the disease in St. Kitts' Acanthuridae and describe its pathology and etiology. Visual surveys demonstrated consistently high adjusted mean prevalence at 3 shallow reefs in St. Kitts in 2017 (38.9\%, 95\% CI: 33.8-43.9) and 2018 (51.5\%; 95\% CI: 46.2-56.9). There were no differences in prevalence across species or reefs, but juvenile fish were less commonly affected than adults. A total of 29 dermatopathy-affected acanthurids were sampled by spearfishing for comprehensive postmortem examination. Digenean metacercariae were dissected from $<1 \mathrm{~mm}$ cysts within pigmented lesions. Using partial $28 \mathrm{~S}$ rDNA sequence data they were classified as Family Heterophyidae, members of which are commonly implicated in black spot disease of other fishes. Morphological features of the parasite were most typical of Scaphanocephalus spp. (Creplin, 1842), and 2 genetic profiles were obtained suggesting more than 1 digenean species. Histologically, pigmented lesions had mild chronic perivascular dermatitis and increased melanophores and melanin density, often centered on encysted digenean metacercariae. In 1 affected $A$. chirurgus, similar metacercariae were histologically identified in skeletal and cardiac muscle. Further research is needed to clarify impact on host fitness, establish the number of heterophyid digenean species that cause black spots on Caribbean fishes and to determine the intermediate and definitive host species.
\end{abstract}

KEY WORDS: Scaphanocephalus - Black spot disease - Heterophyidae - Dermatitis . Dermatopathy $\cdot$ Digenean $\cdot$ Pigment

\section{INTRODUCTION}

Pigmented dermatopathies of fishes, presenting as focal black circular spots or papules, are often associated with cutaneous endoparasites. Metacercariae of digenean trematodes that encyst in the dermis are particularly common etiologies of so-called 'black spot disease', including Cryptocotyle lingua (Family Heterophyidae) in costal cold-water marine fishes (Poynton 2010), and several parasites of the Families

\footnotetext{
*Corresponding author: midennis@rossvet.edu.kn
}

Diplostomatidae and Heterophyidae in temperate and tropical freshwater fishes (Gratzek 2010, Poynton \& Hoffman 2010). In contrast, most reports of black spot disease in marine tropical fish implicate turbellarians rather than digenean metacercariae (Cannon \& Lester 1988, Justine et al. 2009). Furthermore, pigmented skin lesions may also be noninfectious, resulting, for example, from previous skin injury or from neoplasia of chromatophores (Work \& Aeby 2014).

(C) Ross University School of Veterinary Medicine, Adtalem Global Education 2019. Open Access under Creative Commons by Attribution Licence. Use, distribution and reproduction are unrestricted. Authors and original publication must be credited. 
Members of the Family Acanthuridae, including ocean surgeonfish Acanthurus bahianus (also referred to as A. tractus, Bernal \& Rocha 2011), doctorfish A. chirurgus, and blue tang $A$. coeruleus, are herbivores prevalent on Caribbean reefs. They play a key role in structuring benthic communities through macroalgae grazing (Burkepile \& Hay 2010, Marshell \& Mumby 2015). Their depletion can have detrimental impacts on coral reefs by favoring the competitive growth of macroalgae over coral (Edwards et al. 2014, Adam et al. 2015).

A pigmented dermatopathy affecting Caribbean reef fish, especially Acanthuridae, was recently reported that involved several regions across the Caribbean (Bernal et al. 2016, Eierman \& Tanner 2019, Elmer et al. 2019). Prevalences in acanthurids have ranged from around $12 \%$ (Bernal et al. 2016) to $60 \%$ (Eierman \& Tanner 2019, Elmer et al. 2019). The disease was initially assumed to be the result of cutaneous parasitism and turbellarians were first suspected (Bernal et al. 2016). More recently, the dermatopathy has been demonstrated to occur in association with encysted metacercariae of the heterophyid Scaphanocephalus expansus (Creplin, 1842) in 10 species of reef fish in Bonaire (Kohl et al. 2019). The geographical extent of this infection is unknown although one other report from the Caribbean exists, involving a gray snapper Lutjanus griseus from the Florida Keys (Overstreet \& Hawkins 2017). It is unclear if the same etiology is the basis for the pigmented dermatopathy at locations other than Bonaire. In addition, the histopathology of Scaphanocephalus infection has not yet been described and is important for understanding the extent to which the parasite impacts its host.

The objective of this study was to gauge the prevalence of the pigmented dermatopathy in Acanthuridae of St. Kitts and to describe its pathology and etiology.

\section{MATERIALS AND METHODS}

\subsection{Surveys}

The Federation of St. Kitts and Nevis is a 2 island nation in the Leeward Islands of the Lesser Antilles. Surveys were conducted on 3 shallow coastal patch reefs in St. Kitts: Timothy Beach $\left(17.277^{\circ} \mathrm{N}, 62.685^{\circ} \mathrm{W}\right)$, Reggae Beach $\left(17.228^{\circ} \mathrm{N}, 62.631^{\circ} \mathrm{W}\right)$, and White House Bay $\left(17.253^{\circ} \mathrm{N}, 62.659^{\circ} \mathrm{W}\right)$. These reefs reflect similar confluent habitats separated from one another by $<10 \mathrm{~km}$ of shoreline, each at $<10 \mathrm{~m}$ depth with rocky and sandy substrata. These areas were selected because of known prevalence of Acanthuridae, previous observation of the black spot disease, and accessibility from the shoreline.

A $1 \mathrm{~h}$ timed swim, covering approximately 0.7 to $1.0 \mathrm{~km}$, was conducted at each survey site, once in July 2017 and again in July 2018. The surveys were completed by 2 observers, one in 2017 and the other in 2018. Each were similarly trained and used the same methods in order to reduce intra-operator variability. Surveys were undertaken only when visibility was $>15 \mathrm{~m}$. The snorkeler surveyed the reef unidirectionally with attention focused towards oncoming fish to minimize resighting bias. Each observed individual of Acanthurus spp. within around 2.5 to $3.0 \mathrm{~m}$ of either side of the observer was recorded. A. bahianus was distinguished by uniform body color, $A$. chirurgus by the presence of 10 to 12 vertical bars on the body, and A. coeruleus by its overall bright blue color. Fish were classified as juveniles or adults based on estimated size $(<\sim 7 \mathrm{~cm}$ or $\geq \sim 7 \mathrm{~cm}$, respectively). A. coeruleus juveniles were further distinguished by a yellow body or yellow tail. A size reference previously applied to objects of known size at a variety of distances was used to help classify juvenile fish. For each individual, designation of black spot disease was recorded. Designation of black spot disease was based on the presence of 1 or more fairly discrete dark brown to black circular cutaneous lesion(s). Lesion severity score was recorded for each fish, based on the number of lesions on 1 side: apparently healthy (none, score 0 ); mild (1 to 5 lesions, score 1 ); moderate (6 to 10 lesions, score 2 ); or severe (>10 lesions, score 3 ).

While conducting the surveys, or while sampling fish for postmortem examination, any clinical signs associated with the dermatopathy were recorded.

\subsection{Postmortem examination}

Since surgeonfish showing the pigmented dermatopathy were not for sale at the fish market, affected fish were sampled by spearfishing. A total of 29 surgeonfish showing the pigmented dermatopathy (13 A. bahianus, 10 A. coeruleus, and 6 A. chirurgus) were sampled from White House Bay, the study site most conducive to spearfishing, over 6 fishing expeditions from November 2017 through June 2018. Where death was not instantaneous, fish were humanely euthanized by cervical transection with a sharp knife, followed by pithing, in accordance with Ross University Institutional Animal Care and Use Committee approval (protocol approval number 
17.07.34). Fish were transported to the laboratory on ice and a postmortem examination was conducted within $3 \mathrm{~h}$ of sampling. For control fish, $4 \mathrm{~A}$. bahianus, 5 A. coeruleus, and $3 \mathrm{~A}$. chirurgus that lacked skin lesions and were apparently healthy were purchased from a fish market, part in September 2017 and the remaining in November 2018. Information about the location from which they were collected was not available.

Fish were weighed and total length was measured. The number, color, and location of the skin lesions and nodules were recorded. Skin scrapings were prepared from lesions of 3 fish and wet mounts of the sample were cytologically examined. Papules within pigmented foci of 13 fish were examined using fine dissection assisted by a dissecting scope.

A comprehensive necropsy was performed. Gonads were assessed visually for activity and categorized as inactive when they were inconspicuous, flattened or slightly tapered cylinders, or as active when they were enlarged and fusiform to lobed. Samples of apparently healthy skin, skin lesions, fin, stomach, liver, intestine, spleen, gill, brain, and cranial and caudal kidney with body wall were fixed in $10 \%$ neutralbuffered formalin for at least $24 \mathrm{~h}$. Tissues were sectioned and partitioned into cassettes for histological processing using routine methods. Cassettes containing bony elements, including skin, body wall, and gill, were decalcified in Formical-4 (StatLab Medical Products) for 2 to $3 \mathrm{~h}$ prior to processing. Tissues were embedded in paraffin, cut into $4 \mu \mathrm{m}$ thick sections, and stained with hematoxylin and eosin (H\&E).

\subsection{Molecular biology}

During the postmortem examinations of 8 fish (4 A. coeruleus, 2 A. bahianus, and $2 A$. chirurgus), 1 to 2 parasites collected from the fine dissection of papules were stored in $95 \%$ ethanol or DNA lysis buffer for molecular analysis. Total DNA was extracted using a GeneMATRIX DNA isolation kit (EURx) following the tissue protocol and stored at $-20^{\circ} \mathrm{C}$. Polymerase chain reactions $(\mathrm{PCR})$ were used to amplify the variable expansion regions D1-D3 of the 28S rDNA of the parasites using the primers LSU5 (5'-TAG GTC GAC CCG CTG AAY TTA AGC-3') and 1500R (5'-GCT ATC CTG AGG GAA ACT TCG-3') (Littlewood et al. 2000, Olson et al. 2003). Initial sequence reads were confirmed using the additional primers Scaph770fwd (5'-TGC TGC AGG CAT TCG GTC CTC-3'; paired with 1500R, product $640 \mathrm{bp}$ ) and Scaph-860r (5'-ACC AAA CYC GGA CAC GCC AG-3'; paired with LSU5, product $840 \mathrm{bp}$ ). All reactions had annealing temperatures of $55^{\circ} \mathrm{C}$ and extension times of $1 \mathrm{~min}$, and were repeated for 40 cycles. PCR products of the expected sizes were visualized on agarose gels and recovered from the remaining PCR products using a GeneMATRIX PCR products extraction kit (EURx). Sequencing reactions were performed using BigDye $^{\mathrm{TM}}$ Terminator cycle sequencing chemistry utilizing the same oligonucleotide primers that were used for the original PCRs. All products were bidirectionally sequenced at an external laboratory.

Sequences were compared to NCBI's GenBank using the Basic Local Alignment Search Tool (BLAST). These sequences were reviewed for ambiguous base calls and then aligned using BioEdit and ClustalX. From this alignment, a consensus sequence was used for phylogenetic analyses.

Phylogenetic analyses were performed using the maximum likelihood methodology in PhyML (Guindon et al. 2010) with the automatic smart model selection (selection criterion: Akaike's information criterion [AIC]), running the general time-reversible substitution model (GTR + G6 + I) with 1000 bootstrap repeats. Bayesian inference (BI) analysis was done using MrBayes v. 3.2.6 (Ronquist \& Huelsenbeck 2003). For the BI analysis, models of nucleotide substitution were first evaluated for the alignment using MrModeltest v. 2.2 (Nylander et al. 2004). The most parameter-rich evolutionary model based on the AIC was the general time-reversible GTR + I + G model of evolution. Therefore, the settings used for the analysis were nst $=6$, with the gamma-distributed rate variation across sites and a proportion of invariable sites (rates $=$ invgamma). The priors on state frequency were left at the default setting (Prset statefreqpr = dirichlet $(1,1,1,1))$, and Mitotrema anthostomatum Manter, 1963 (AY222229), a phylogenetically related digenean from the superfamily Opistorchioidea and generally accepted to be part of the Family Cryptogonimidae, was set as the outgroup. Posterior probability distributions were generated using the Markov Chain Monte Carlo (MCMC) method with 4 chains being run simultaneously for 2000000 generations. Burn in was set at 5000 and trees were sampled every 100 generations. Consensus trees were viewed in FigTree (Tree Figure Drawing Tool Version 1.4.2) (http://tree.bio.ed.ac.uk/software/figtree/).

\subsection{Statistical analysis}

Fulton's index was used to compare condition among fish subjected to postmortem examination 
and was calculated as follows: $K$ (condition factor) = $100 \times W(\mathrm{~g}) / L(\mathrm{~cm})^{3}$ (Le Cren 1951, Ricker 1975) Median weight $(W)$, length $(L)$, and $K$ were compared among apparently healthy and pigmented dermatopathy-affected fish using a Kruskal-Wallis test. Fish that had lesions affecting gills, liver, spleen, kidney, gastrointestinal tract, or brain were classified as having visceral pathology and the association between visceral pathology and black spot disease was compared using a Pearson's chi-square test. Prevalence of lesions and mean lesion severity score were calculated for each swim. To take into account the variation in count among observers, weighted mean prevalence and weighted mean lesion severity score were calculating overall and for different factors (species, year, reef, age) by inclusion of a weight by swim. The inverse of the variance of each swim parameters was used as weight. For prevalence, if no lesions were observed during the swim (standard error $=0$ ), a value of 0.5 was added to numerator (number of lesions) and denominator (number of individuals) to avoid division of 0 . Mean lesion severity score was calculated omitting those without lesions (i.e. apparently healthy, score 0). Comparisons between groups were done using the weighted $95 \%$ confidence intervals (CI). Data were managed and analyzed with Microsoft Excel® and R software (R Core Team 2017). All tests were at the significance level of alpha $=0.05$.

\section{RESULTS}

\subsection{Surveys}

Black spot disease was highly prevalent in Acanthuridae across 3 coastal reefs in St. Kitts (Fig. 1, Table 1) with no significant difference between species or reef. Weighted mean prevalence was higher in adults than in juvenile. Prevalence increased significantly in 2018 compared to 2017 only for Acanthurus chirurgus. No difference in mean severity was observed.

Clinical signs of affected fish observed during this study included flashing (i.e. rubbing sides of body on substrate) and brief episodes of rapid erratic swimming. Flashing was not observed in unaffected fish.

\subsection{Pathology}

Comprehensive postmortem examination was performed on 41 fish, including 12 control fish lacking
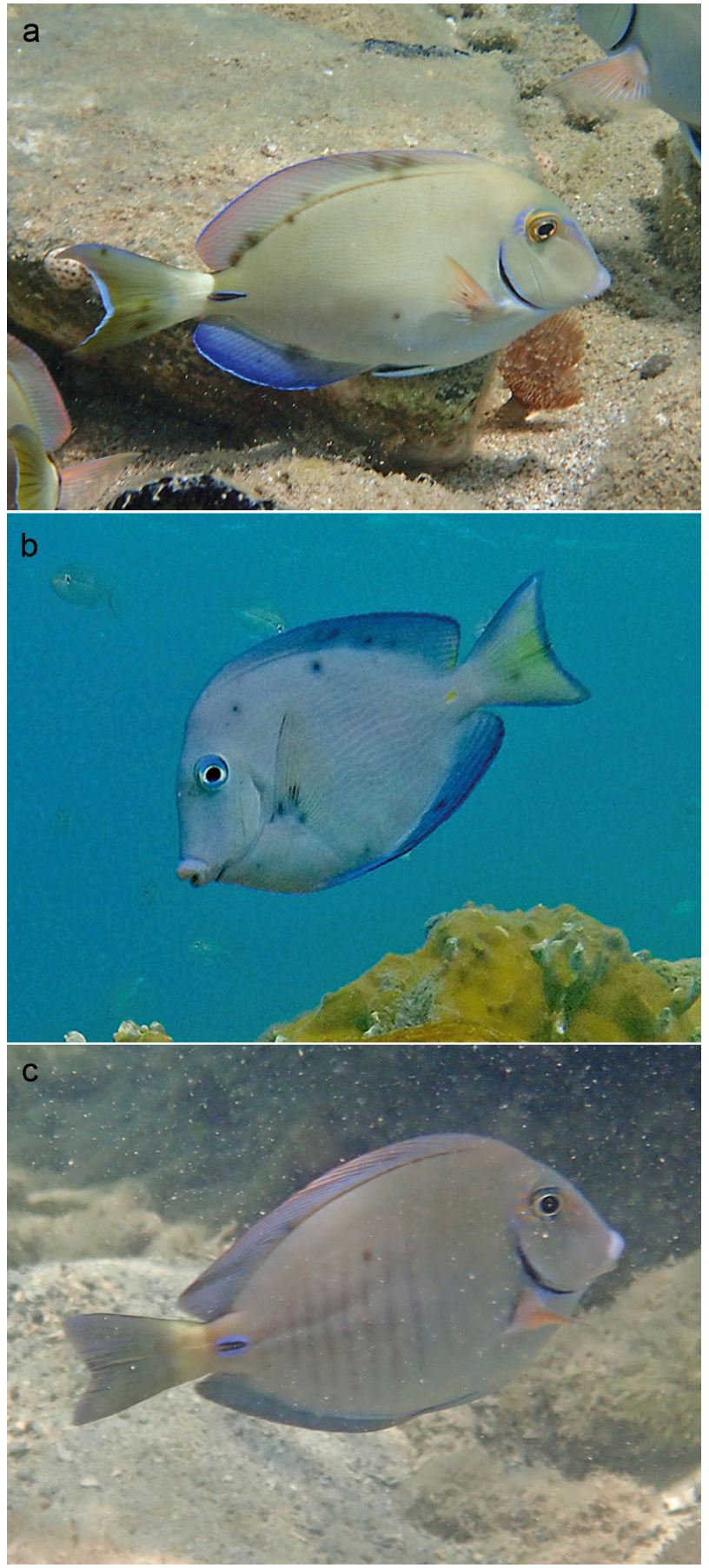

Fig. 1. Black spot disease observed in St. Kitts' Acanthuridae. (a) Acanthurus bahianus, Timothy Beach; (b) A. coeruleus, White House Bay; (c) A. chirurgus, Reggae Beach. Image credit for (b): Gregory Hartman

the pigmented dermatopathy and 29 fish affected with the dermatopathy (Table 2). Study fish included 15 fish with mild, 9 with moderate, and 5 with severe black spot disease, based on the highest number of lesions affecting a side. Median weight and length 
Table 1. Inverse variance-adjusted prevalence of black spot disease multifocal pigmented dermatopathy and inverse variance adjusted mean lesion severity score across reef site, size class, and species in visual surveys of adult and juvenile Acanthurus spp. (Family Acanthuridae) on Reggae

Beach, Timothy Beach and White House Bay reefs in 2017 and 2018

\begin{tabular}{|lrrrr|}
\hline & $\mathrm{N}$ & $\begin{array}{c}\text { Number } \\
\text { affected }\end{array}$ & $\begin{array}{c}\text { Adjusted mean } \\
\text { prevalence }(\%) \\
(95 \% \mathrm{CI})\end{array}$ & $\begin{array}{l}\text { Lesion severity } \\
\text { score }(95 \% \mathrm{CI})\end{array}$ \\
\hline Total & & & & \\
Year & 669 & 303 & $44.8(41.2-48.5)$ & $1.23(0.84-1.63)$ \\
2017 & & & & \\
2018 & 349 & 138 & $38.9(33.8-43.9)$ & $1.25(0.71-1.79)$ \\
Species & 320 & 165 & $51.5(46.2-56.9)$ & $1.18(0.71-1.65)$ \\
A. bahianus & & & & \\
2017 & 332 & 154 & $45.3(40.1-50.5)$ & $1.21(0.84-1.59)$ \\
2018 & 136 & 55 & $38.5(30.6-46.4)$ & $1.43(0.76-2.09)$ \\
A. chirurgus & 196 & 99 & $50.4(43.5-57.4)$ & $1.17(0.72-1.63)$ \\
2017 & 45 & 19 & $33.5(22.2-44.9)$ & $1.30(0.68-1.93)$ \\
2018 & 36 & 12 & $24.6(12.0-37.2)$ & $1.29(0.24-2.33)$ \\
A. coeruleus & 9 & 7 & $71.4(45.7-97.5)$ & $1.30(0.54-2.07)$ \\
2017 & 292 & 130 & $44.7(39.1-50.2)$ & $1.14(0.87-1.41)$ \\
2018 & 177 & 71 & $40.1(32.9-47.3)$ & $1.12(0.79-1.45)$ \\
Size & 115 & 59 & $51.4(42.7-60.1)$ & $1.18(0.70-1.66)$ \\
Adult & & & & \\
Juvenile & 465 & 231 & $50.3(46.0-54.7)$ & $1.27(0.81-1.72)$ \\
Reef & 160 & 60 & $34.0(27.0-41.0)$ & $1.18(0.77-1.59)$ \\
Reggae & & & & \\
Timothy & 214 & 102 & $46.9(40.5-53.3)$ & $1.24(0.67-1.81)$ \\
White House Bay & 223 & 105 & $45.0(28.7-51.2)$ & $1.14(0.58-1.71)$ \\
a Size was not categorized for 44 individuals & \\
\hline
\end{tabular}

Table 2. Condition factor $\left(K_{;}\right.$mean $\left.\pm \mathrm{SD}\right)$ and prevalence (no. affected/no. assessed) of cutaneous pathology identified in postmortem examinations of apparently healthy Caribbean Acanthurus spp. compared with those affected by black spot disease

\begin{tabular}{|lcccc|}
\hline Species & $\mathrm{N}$ & $\begin{array}{c}K \\
\left(\mathrm{~g} \mathrm{~cm}^{-3}\right)\end{array}$ & $\begin{array}{c}\text { Chronic } \\
\text { dermatitis } \\
(\%)\end{array}$ & $\begin{array}{c}\text { Encysted } \\
\text { metacercaria within } \\
\text { pigmented areas }\end{array}$ \\
\hline Apparently healthy & 12 & $2.4 \pm 0.5$ & $0 / 11(0)$ & - \\
A. bahianus & 4 & $2.4 \pm 0.7$ & $0 / 4(0)$ & - \\
A. chirurgus & 3 & $2.4 \pm 0.1$ & $0 / 2(0)$ & - \\
A. coeruleus & 5 & $2.8 \pm 0.3$ & $0 / 5(0)$ & - \\
Black spot disease & 29 & $2.2 \pm 0.3$ & $26 / 29(90)$ & $15 / 29(52)$ \\
A. bahianus & 13 & $2.0 \pm 0.2$ & $11 / 13(85)$ & $8 / 13(62)$ \\
A. chirurgus & 6 & $2.1 \pm 0.2$ & $5 / 6(83)$ & $1 / 6(17)$ \\
A. coeruleus & 10 & $2.5 \pm 0.2$ & $10 / 10(100)$ & $6 / 10(60)$ \\
Total & 41 & $2.2 \pm 0.6$ & - & - \\
\hline
\end{tabular}

(2.4, range: $1.7-3.2)$ relative to black spot disease-affected fish (2.3, range: $1.8-2.8$; $\mathrm{p}=0.3)$.

The circular brown-black cutaneous foci, ranged from 5 to $15 \mathrm{~mm}$ in diameter, and their intensity and margin distinction were somewhat lessened out of the water than observed on the live fish in situ, prior to sampling. The pigmented foci were distributed mostly on the fins and, to a lesser extent, the body or head, and frequently contained a central 1 to $2 \mathrm{~mm}$ diameter papule evident under a dissecting microscope. In 8 fish, 69 pigmented foci were examined under the dissecting microscope, and papules were identified in 22/69 (32\%) lesions. Wet mounts of skin scrapings from pigmented foci failed to identify ectoparasites or other etiologic agents. Microscopeguided fine dissection of pigmented foci containing papules demonstrated the presence of an approximately 1 to $1.5 \mathrm{~mm}$ cyst situated beneath the epidermis and scales (Fig. 2). The cyst contents consistently comprised a metazoan parasite with distinctive morphological features, consistent with a digenean metacercaria of the Family Heterophyidae (Fig. 3). These ranged from approximately 975 to $1020 \mu \mathrm{m}$ in length and had a broadened fan-shaped anterior end with wing-like expansions, which ranged from approximately 1050 to $1150 \mu \mathrm{m}$ in width. The anterior end in particular is characteristic of Scaphanocephalus spp. (Jägerskiöld 1904, Pearson 2008), and the fan shape of the anterior end is more typical of $S$. expansus than $S$. australis and $S$. adamsi (Iwata 1997).

Histologically, mild chronic dermatitis was microscopically evident in samples of pigmented skin lesions in 26/29 fish (90\%), but not in the skin of apparently healthy control fish (Table 2). The lesion was microscopically similar regardless of location (i.e. fin versus body) and were greater for apparently healthy (179.5 g, range: 30-331 g; $19 \mathrm{~cm}$, range: $12-24.5 \mathrm{~cm})$, relative to black spot disease-affected fish (34 $\mathrm{g}$, range: $12-95 \mathrm{~g}$; $11 \mathrm{~cm}$, range: 8-17 cm; p = 0.001 and 0.000, respectively). There was no significance difference in median condition index $(K)$ of apparently healthy consisted of an infiltrate of mononuclear leukocytes (i.e. predominantly lymphocytes and histiocytes) in perivascular areas of the dermis $(24 / 29,83 \%)$ or epidermis (23/29, 79\%) (Fig. 4), and marginally or mildly increased density of dermal melanophores. In 15 fish, a total of 39 encysted metacercariae were his- 


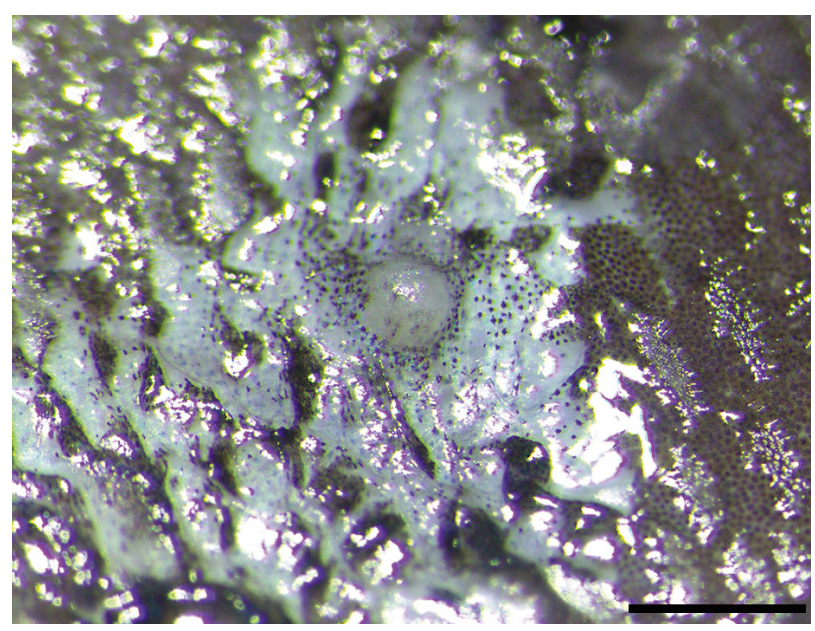

Fig. 2. Pigmented dermatopathy in Acanthurus coeruleus. Scales have been dissected away from the region of a papule to reveal a dermal cyst. Scale bar $=2000 \mu \mathrm{m}$

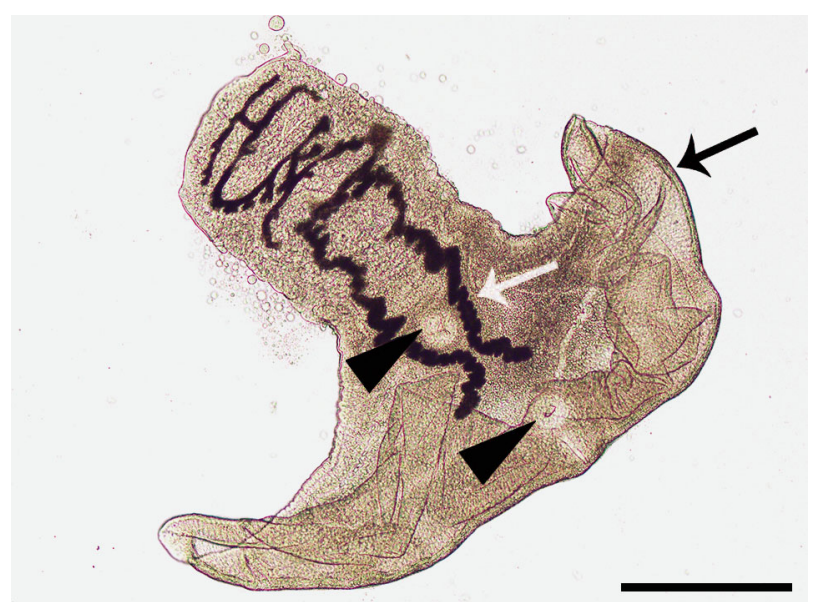

Fig. 3. Wet mount of parasite dissected from a cyst in pigmented dermatopathy in Acanthurus coeruleus. Note wingshaped anterior end (black arrow), paired pigmented cecae (white arrow), and 2 suckers (arrowheads), characteristic of Scaphanocephalus spp. metacercariae. Scale bar $=250 \mu \mathrm{m}$

tologically observed in samples of pigmented skin lesions. The cysts averaged $543 \mu \mathrm{m}$ in diameter (range 214-909, SD $159 \mu \mathrm{m}$ ), had a thick hyaline capsule averaging $42 \mu \mathrm{m}$ thick (range 11-82, SD $16.9 \mu \mathrm{m})$, and contained a larval trematode with a thin non-ciliated tegument adjoining an underlying smooth muscle layer, parenchymatous body cavity, and poorly discernable viscera, consistent with a metacercaria (Fig. 5). Encysted metacercariae were bordered by leukocyte infiltrate in 27/39 (69\%) of cysts, which was comprised of mononuclear leukocytes similar to the marginating dermis. When present, the infiltrate was mild in $21 / 27$ (78\%) and moderate in 6/27 (22\%). In 31/39 (80\%) cysts, dermal

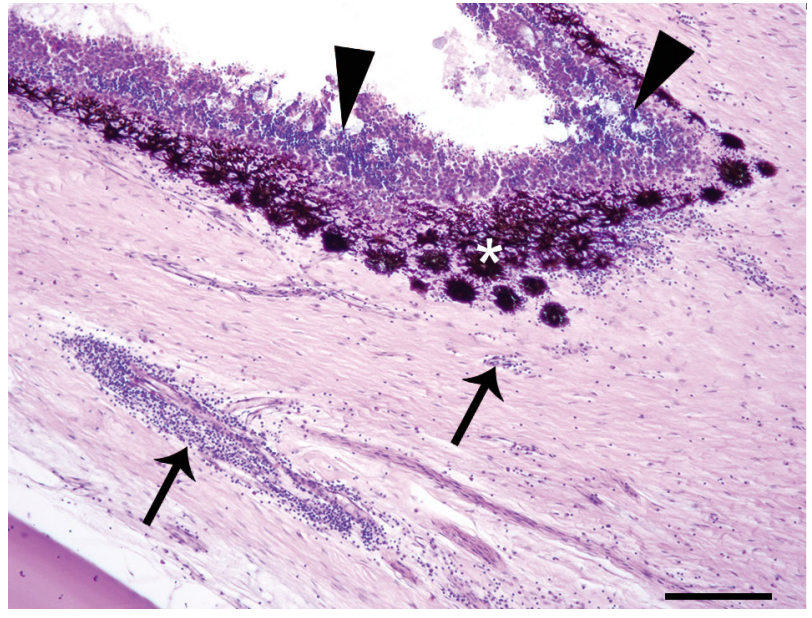

Fig. 4. Chronic dermatitis in a fin affected by pigmented dermatopathy in Acanthurus coeruleus. Mononuclear leukocytes form aggregates within the epidermis (arrowheads) and perivascular areas of dermis (arrows). Melanophores and melanin pigment are of increased density (asterisk). H\&E stain. Scale bar $=100 \mu \mathrm{m}$

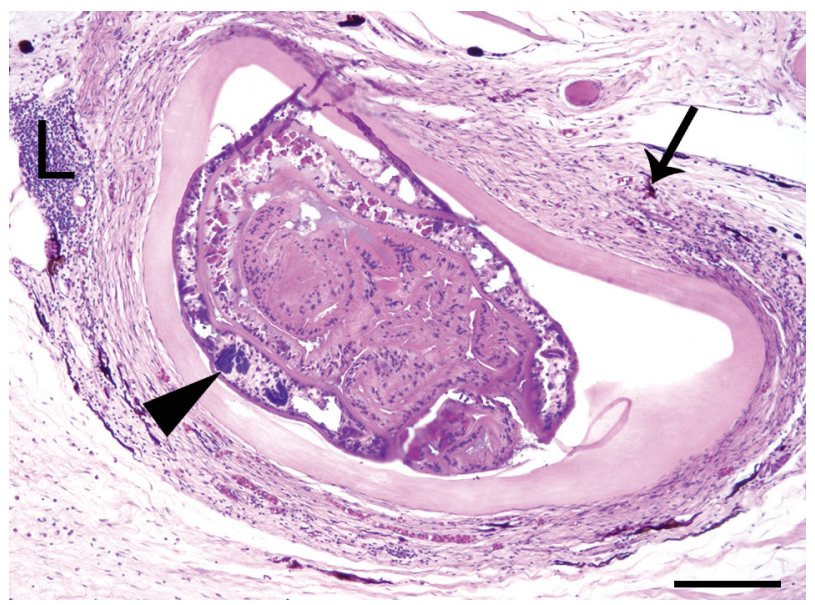

Fig. 5. Metacercaria (arrowhead) encysted within the dermis in a region of skin affected by pigmented dermatopathy associated with Acanthurus coeruleus. Note leukocyte infiltrate $(\mathrm{L})$ and increase in melanophores and melanin density within the connective tissue surrounding the cyst (arrow). H\&E stain. Scale bar $=100 \mu \mathrm{m}$

melanophores and fine brown granular pigment, which stained black with Fontanna Masson stain (indicating melanin), were increased around the cysts, to a mild extent in 16/31 (52\%) cysts with dermal pigmentation and moderate in 15/31 (48\%). Encysted metacercariae of similar size and morphology were also histologically observed in skeletal and cardiac muscle in 1 fish (of 40 where skeletal muscle, and 15 where heart were histologically evaluated), an A. chirurgus with the pigmented dermatopathy and similar cutaneous metacercariae. Turbellarians, his- 
tologically distinguished from metacercariae by the presence of ciliated tegument (Cannon \& Lester 1988), were not identified in any fish.

A variety of other lesions were observed in organs other than skin. Mild chronic perivascular myositis was observed in 11/29 (37.9\%) and intestinal distomiasis was seen $4 / 18(22.2 \%)$ of black spot diseaseaffected fish, while neither were seen in any control fish. Lesions observed in both apparently healthy and black spot disease-affected fish, respectively, included lamellar monogeneans (1/10, $10 \%$; 4/23, $17.4 \%)$, intramyocytic myxozoan cysts $(1 / 11,9.1 \%$; $3 / 29,10.3 \%)$, mild focal chronic encephalitis (3/9, $33.3 \%$; 9/25, 36\%), mild chronic periductular hepatitis $(3 / 11,27.3 \% ; 9 / 19,47.4 \%)$, and other lesions $(7 / 12,58.3 \% ; 6 / 29,20.6 \%)$.

Active gonads were only identified in 2 female apparently healthy (control) A. coeruleus sampled in September 2017 and November 2018.

Fish that had lesions affecting gills, liver, spleen, kidney, gastrointestinal tract, or brain were classified as having visceral pathology. There was no association between visceral pathology and black spot disease $\left(\chi^{2}=0.26, p=0.6\right)$. bers MN160569 and MN160570 and were compared to known sequences in the DNA databases using BLAST. One sequence (MN160570, n = 2) had a 99.9\% similarity to $S$. expansus (MK680936), whilst the other (MN160569, $\mathrm{n}=10$ ) only had a $97.9 \%$ identity to same sequence. The next closest relative for both sequences was the heterophyid digenean Cryptocotyle lingua, with an identity to the 2 novel sequences of $96.68 \%$ and $96.45 \%$ respectively. This suggests that the 2 novel sequences generated here represent closely related but different species, one of which has recently been identified as S. expansus (MK680936) (Kohl et al. 2019).

The phylogenetic tree (Fig. 6) places the 2 novel sequences in a clade with $C$. lingua and Euryhelmis costaricensis, both digeneans from the Family Heterophyidae.

\section{DISCUSSION}

The pigmented dermatopathy in St. Kitts' Acanthuridae reflects a focal dermatitis caused by encysted digenean metacercariae, consistent with a

\subsection{Molecular biology}

Two contiguous 28S rDNA sequences of 1354 and $1357 \mathrm{bp}$ were obtained from the parasites in this study. Consensus sequence alignment confirmed that 10 of the 12 sequences were identical. However, 2 further identical sequences (from 2 separate digeneans) from 1 doctorfish A. chirurgus, the fish with encysted metacercariae identified histologically within skeletal and cardiac muscle, were dissimilar to the others by $26 \mathrm{bp}$ (including 3 gaps), amounting to a similarity between the 2 types of approximately $98 \%$. The excysted metacercariae were not morphologically assessed in this fish, but the cysts were of similar size to other Scaphanocephalus cysts, and those examined histologically were microscopically similar to those of other fish in this study.

The 2 novel sequences generated from this study were submitted to GenBank under the accession num-

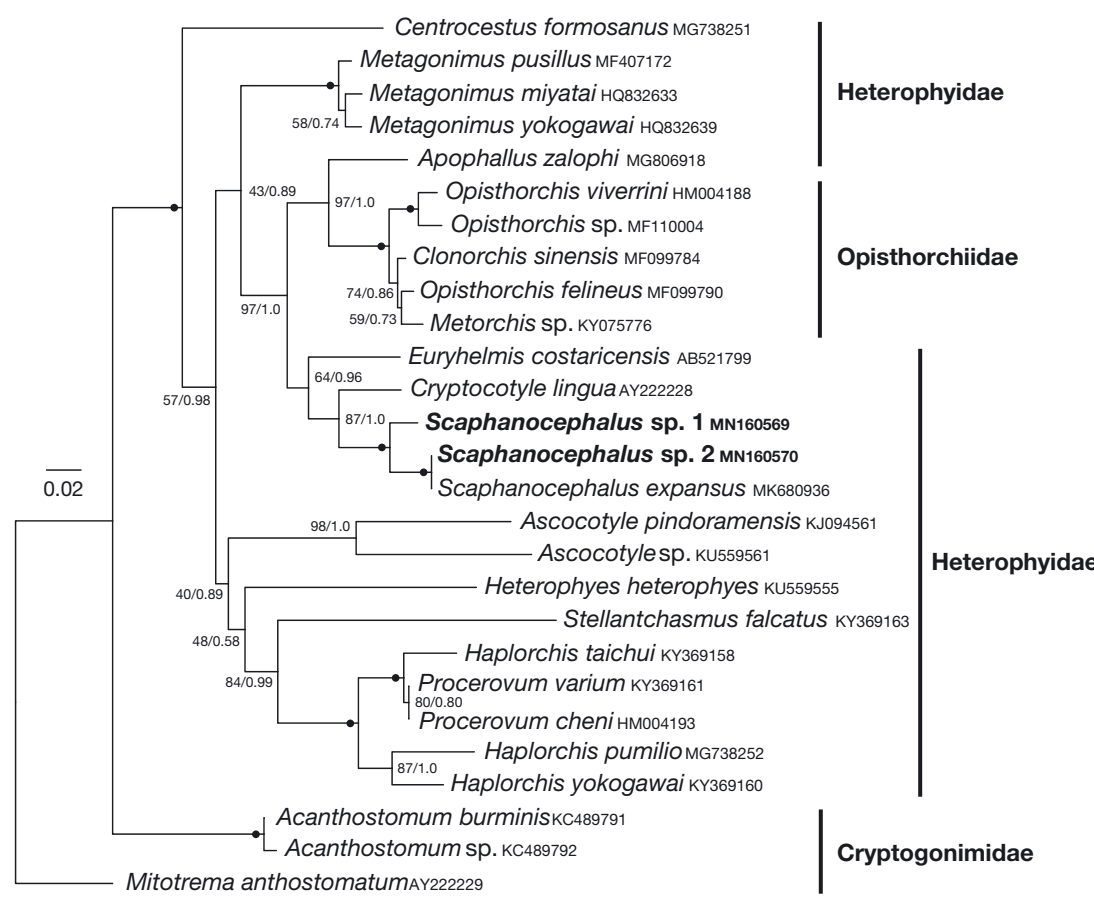

Fig. 6. Maximum likelihood topology of 27 digenean taxa from the sub-order Opisthorchiata with a focus on members of the Heterophyidae. Nodes show bootstrap support values and posterior probabilities, solid black dots indicate full support for that node. Novel sequences from this study are in bold and group with Scaphanocephalus expansus and Cryptocotyle lingua, both heterophyid digeneans known to cause black dermal skin lesions in multiple fish in the Atlantic. Mitotrema anthostomatum was used to root the tree. All GenBank accession numbers are given after the taxon branch labels 
diagnosis of black spot disease. In this study, all parasites excysted from the pigmented cutaneous lesions from nearly half of all fish subjected to postmortem examination $(13 / 29,45 \%)$ were of a single morphotype, characteristic of digenean metacercariae from the Heterophyidae, being most typical of Scaphanocephalus spp., the only trematode taxon characterized by anterior wing-shape expansions (Pearson 2008). Furthermore, intralesional metacercariae cysts of similar size were histologically evident in the pigmented skin lesions of acanthurids (identified in $15 / 29,52 \%$ of fish), and every excysted metacercaria subjected to molecular analysis $(n=12)$ yielded similar results. Taken together, these data indicate that heterophyid dermatitis accounts for the vast majority of black spot disease in St. Kitts' shallow-dwelling Acanthuridae. Our metacercariae are morphologically similar to $S$. expansus, described in black spot disease affecting Acanthuridae and other reef fish in Bonaire (Kohl et al. 2019) and a gray snapper Lutjanus griseus from the Florida Keys (Overstreet \& Hawkins 2017), indicating that Scaphanocephalus spp. is widespread in the Caribbean. Kohl et al. (2019) morphologically examined 1354 metacercariae from 40 fishes and no other parasite was identified in pigmented cutaneous foci. We demonstrated 2 different genetic profiles from encysted metacercariae indicating there is likely more than 1 species of Scaphanocephalus causing the black spot disease in St. Kitts. Our predominant profile (10/12 sequenced metacercariae) has a different DNA sequence to $S$. expansus in Bonaire; however, that study only molecularly evaluated 2 metacercaria from redtail parrotfish Sparisoma chrysopterum (Kohl et al. 2019). The identification by Kohl et al. (2019) was based on morphological comparison of Bonaire metacercariae to archived voucher specimens of $S$. expansus adults and a metacercaria. However, given the lack of DNA data from the type localities and hosts of Scaphanocephalus spp. globally, species-level identification of the Caribbean samples remains uncertain. Broader genetic identification of the heterophyid(s), and potentially other etiologies, causing black spot disease throughout the region is needed to more definitively classify the Caribbean Scaphanocephalus spp. and the extent to which more than 1 etiologic agent is involved.

Most digenean trematodes causing black spot disease have an indirect life cycle requiring 3 hosts, typically a mollusk first intermediate host, a finfish second intermediate host, and a piscivorous avian definitive host. In digenean life cycles, first intermediate hosts (mollusks) are widely accepted as having a far more host-specific association than other life cycle stages (Adema \& Loker 2015), and are a key factor in dictating the parasite's geographical distribution. The first intermediate host of Scaphanocephlus is unknown, but in Cryptocotyle spp., the most closely related member of the Family Heterophyidae, the first intermediate host is a marine gastropod (Littorina littorea) (Stunkard 1930). Adult $S$. expansus have only been reported from the intestine of osprey Pandion haliaetus, but from a wide geographic range, including the USA, Europe, and North Africa (Hoffman et al. 1953, Dubois et al. 1960, Kinsella et al. 1996, Foronda et al. 2009). Scaphanocephalus appears to show little specificity for its second intermediate host. Cutaneous metacercaria of Scaphanocephalus have been demonstrated in several species of tropical or subtropical marine fish of the Indopacific, Atlantic, and Caribbean, including various goatfishes, damselfishes, trumpetfishes, wrasse, parrotfishes, pufferfishes, and hogfishes, among others (Tubangui 1933, Hutton 1964, Skinner 1978, Inohuye Rivera 1995, Iwata 1997, Bullard \& Overstreet 2008). Only recently was Scaphanocephalus demonstrated in association with black spot disease in Caribbean fish, including 35 acanthurids, 4 scarids, 3 bar jack Caranx ruber, and single instances in 5 other species (Overstreet \& Hawkins 2017, Kohl et al. 2019). While a similar pigmented dermatopathy has been visually documented in many additional species of Caribbean fish (Bernal et al. 2016, Eierman \& Tanner 2019, Elmer et al. 2019), it should not necessarily be assumed that these observations are caused by $S$. expansus, as the present study implicates the involvement of at least 2 species of Scaphanocephalus and species identifications are not fully confirmed. Further research is needed to determine the identity of the parasites involved in other Caribbean fish with multifocal cutaneous pigmentation. A Google Images search indicated that multifocal cutaneous pigmentation has been observed on Acanthurus bahianus throughout the Caribbean, from as early as 1985 (Elmer et al. 2019), and Scaphanocephalus metacercariae have been known in Caribbean fishes since the 1960s (Hutton 1964, Skinner 1978). While Scaphanocephalus black spot disease therefore does not seem new to the Caribbean, the increasing reports of the pigmented dermatopathy, and apparently increasing prevalence over a short timeframe in some regions (Eierman \& Tanner 2019, Elmer et al. 2019), has garnered concern for an emerging disease scenario. However, meaningful speculation on disease ecology is limited by the uncertainty around the different etiologies that may be involved among locations. 
In the present study, subsequent surveys demonstrated black spot disease to be consistently highly prevalent in shallow coastal acanthurids across 2 years (adjusted mean prevalence of 38.9\% [95\% CI: 33.8-43.9] in 2017, and 51.5\% [95\% CI: 46.2-56.9] in 2018). Prevalences were higher than those reported in Google Images surveys of the Eastern Caribbean (14.1\%; Elmer et al. 2019) and visual surveys of a grossly similar pigmented dermatopathy in acanthurids of Curaçao in 2013 (11.8\%; Bernal et al. 2016). In contrast, visual surveys of $A$. bahianus showed greater prevalence in Bonaire in 2012 and 2017 (59.3\% and $68.7 \%$, respectively; Elmer et al. 2019) and in Belize in 2014 to 2016 (60.1\%; Eierman \& Tanner 2019) than was observed in St. Kitts in 2017 to 2018 (adjusted mean prevalence of $45.3 \%$ [95\% CI: 40.1-50.5]). However, comparisons of prevalence across studies may be biased by overall methodology, especially as other studies have not adjusted prevalence estimates derived from multiple divers using inverse variance weighting. Adjusted mean prevalence was not significantly different among species or locations in St. Kitts. However, it was lower in juvenile (34.0\% [95\% CI: 27.0-41.0]) than adult (50.3\% [95\% CI: 46.0-54.7]) acanthurids. This may be a reflection of the length of time required for a lesion to develop at a site of cutaneous cercarial penetration, the fact that older animals have greater opportunity to accrue multiple infections over time, or the juvenile integument possibly being less permissive to cercarial penetration. Age categorization was visually estimated in the present study and future studies could confirm the relationship between age and infection status using laser photogrammetry to more accurately assess size (Yoshihara 1997).

The pathology of Scaphanocephalus dermatitis is consistent with piscine black spot disease caused by other digeneans. The disease consists of pigment deposition centered on encysted metacercariae (Gratzek 2010, Poynton 2010, Poynton \& Hoffman 2010), a predictable response to infectious cercaria directly penetrating the epidermis. Since the metacercariae become isolated within a cyst wall, there is characteristically little inflammatory response to the infection (McQueen et al. 1973). In contrast, Scaphanocephalus cysts were typically surrounded by inflammation, and chronic perivascular dermatitis was often present in adjacent skin, suggesting that black spot disease incited by Scaphanocephalus may not be as benign as that caused by other heterophyids. In addition, while conducting surveys, clinical signs of pruritus were occasionally observed in acanthurids with black spot disease, including flashing (i.e. rubbing sides of body on substrate) and brief episodes of rapid erratic swimming, indicating that the dermatitis, while typically mild, is not subclinical. Some foci of cutaneous pigmentation consisted histologically of chronic dermatitis lacking metacercariae, a finding that was absent in skin samples from control fish. Cutaneous pigmentation and dermatitis without metacercarial cysts may be a reflection of stage of disease (prior to encystation, or following excystation), the cysts failing to be represented in a histological section due to their small size, or potentially another unidentified etiology. Many fish also had mild perivascular inflammation within body wall skeletal muscle underlying the cutaneous lesion, a finding that was not observed in control fish and is presumptively a localized response to Scaphanocephalus infection. Although metacercariae were never found encysted in apparently healthy skin, a detailed search for cutaneous metacercariae in areas of dermatopathy-unaffected skin was not undertaken; therefore, the proportion of metacercariae which induce pigmentation or dermatitis is uncertain. Nonetheless, our results represent the first report of the histopathology of Scaphanocephalus black spot disease. The metacercariae are associated with mild dermatitis, but otherwise findings are similar to black spot disease caused by other digeneans, where there is little impact on the fish intermediate host.

Black spot disease is generally considered to cause little harm to the host, except for heavy infections, infections in young fish, or those involving the eyes, gill, and internal viscera (Poynton 2010). In the present study, the mean lesion severity score assessed during surveys was 1.23 (95\% CI: 0.84-1.63), indicating that most affected fish have a mild form of disease. While lesion severity scores were estimated by assessing only 1 side of the fish, an obvious difference in lesion number between body sides was not appreciated during field observations or postmortem examinations, and is considered unlikely to have biased severity scores. Moreover, histologically, the dermatitis was mild overall and the metacercarial infection was mostly confined to the integument. However, similar metacercarial cysts were histologically identified in the heart and muscle of $1 \mathrm{~A}$. chirurgus with Scaphanocephalus dermatitis, presumptively the same parasite involving the skin (although not morphologically evaluated), suggesting more serious forms of the infection can occur. In this $A$. chirurgus, the dermal metacercariae were molecularly distinct and similar to those of Bonaire (sp. 2 in Fig. 6) but Kohl et al. (2019) did not report involvement of heart or muscle. 
While not a primary focus of this study, an attempt was made to explore the relationship between infection and host fitness. To reduce the number of fish that would be sacrificed for this study, apparently healthy control fish were sourced from a fishing market. It follows that the control fish were larger (in both weight and length) than disease-affected fish. Therefore, body condition was used as an indication of fitness rather than size. Condition index $(K)$ of fish with black spot disease trended lower than apparently healthy fish. However, the difference in median $K$ was not statistically significant and may have been influenced by gonad weight (Le Cren 1951). Moreover, the presence of multifocal cutaneous pigmentation is thought to make the infected intermediate host more visible to the piscivorous definitive host (Overstreet \& Hawkins 2017), which could also reduce fitness. Interestingly, none of the fish with black spot disease sampled by this study were found to have mature gonads by visual assessment despite 27 (93\%) being sampled during February to June, the time of year when Caribbean acanthurids are most reproductively active (Munro et al. 1973). Length at maturity is not known for each species, and given that fish were sampled from an inshore location where young Caribbean acanthurids tend to settle (Robertson et al. 2005), it is possible that the lack of reproductive activity was a reflection of size or age rather than a consequence of black spot disease. Future research aiming to determine the impact of Scaphanocephalus infection on host fitness should give further attention to the potential relationships with body condition, survival, and lesion progression (i.e. studies of tagged fish), and gonad activity, preferably using a larger sample size and gonadosomatic index or gonad histology for a more accurate assessment of the latter.

This study allowed the opportunity to assess background diseases in free-living Acanthuridae. Other lesions identified included encephalitis, lamellar monogeneans, intestinal distomiasis, chronic periductular hepatitis, and intramuscular myxozoan cysts. These lesions were all very mild and of questionable physiological significance, yet provide some insight into other diseases that may impact acanthurid populations. The lamellar monogeneans are likely Neobenedenia melleni based on size, location, and known occurrence in Caribbean Acanthuridae (Sikkel et al. 2009). A number of digenea are known to infect the intestine of Caribbean acanthurids, including Hapladena acanthuri, H. varia, and Monorchimacradena acanthuri, (Fischthal 1978, Dyer et al. 1985, Nahhas 1993, Andres et al. 2018), but their identity cannot be reliably differentiated in histological sections. The morphological features of the myxozoans infecting skeletal myocytes were similar to histozoic myxosporeans such as Kudoa sp. (Kristmundsson \& Freeman 2014) and, to the authors' knowledge, have not yet been reported in Acanthuridae. The etiologies of periductular hepatitis and encephalitis remain unknown and further investigation could benefit from cytological examination of wet mounts and impression smears of associated tissues for identification of histologically obscure protists.

Acknowledgements. This work was supported by an intramural grant from Ross University School of Veterinary Medicine, Center for Conservation Medicine and Ecosystem Health (Grant number 43006-2019). The authors thank the St. Kitts Department of Marine Resources for their support and are grateful for the histology performed by David Hilchie, and for the assistance with dissections and surveys provided by Alexandra Gutierrez and Katerina Kuscevic.

\section{LITERATURE CITED}

Adam TC, Burkepile DE, Ruttenberg BI, Paddack MJ (2015) Herbivory and the resilience of Caribbean coral reefs: knowledge gaps and implications for management. Mar Ecol Prog Ser 520:1-20

Adema CM, Loker ES (2015) Digenean-gastropod host associations inform on aspects of specific immunity in snails. Dev Comp Immunol 48:275-283

Andres MJ, Pulis EE, Curran SS, Overstreet RM (2018) On the systematics of some marine haploporids (Trematoda) with the description of a new species of Megasolena Linton, 1910. Parasitol Int 67:805-815

*Bernal MA, Rocha LA (2011) Acanthurus tractus Poey, 1860, a valid western Atlantic species of surgeonfish (Teleostei, Acanthuridae), distinct from Acanthurus bahianus Castelnau, 1855. Zootaxa 2905:63-68

Bernal MA, Floeter SR, Gaither MR, Longo GO and others (2016) High prevalence of dermal parasites among coral reef fishes of Curaçao. Mar Biodivers 46:67-74

Bullard S, Overstreet R (2008) Digeneans as enemies of fishes. In: Eiras J, Segner H, Wahil T, Kapoor BG (eds) Fish diseases. Science Publishers, Enfield, NH, p 817-976

*Burkepile DE, Hay ME (2010) Impact of herbivore identity on algal succession and coral growth on a Caribbean reef. PLOS ONE 5:e8963

* Cannon LRG, Lester RJG (1988) Two turbellarians parasitic in fish. Dis Aquat Org 5:15-22

*Doubois G, Inglis WG, Chabaud AG, Mawson PM, Doby JM, Bernard C (1960) Redécouverte de Scaphanocephaus expansus. Ann Parasitol Hum Comp 35:426-434

Dyer WG, Williams EH, Williams LB (1985) Digenetic trematodes of marine fishes of the western and southwestern coasts of Puerto Rico. Proc Helminthol Soc Wash 52: 85-94

Edwards CB, Friedlander AM, Green AG, Hardt MJ and others (2014) Global assessment of the status of coral reef herbivorous fishes: Evidence for fishing effects. Proc R Soc B 281:20131835 
Eierman LE, Tanner CE (2019) Prevalence and severity of cutaneous pigmented lesions on ocean surgeonfish, Acanthurus bahianus, at Turneffe Atoll and Glover's Reef of Belize. Caribbean Naturalist No. 62

Elmer F, Kohl ZF, Johnson PTJ, Peachey RJB (2019) Black spot syndrome in reef fishes: using archival imagery and field surveys to characterize spatial and temporal distribution in the Caribbean. Coral Reefs 38:1303

Fischthal JH (1978) Some digenetic trematodes of marine fishes from the barrier reef and reef lagoon of Belize. Zool Scr 6:81-88

Foronda P, Santana-Morales MA, Feliu C, Valladares B (2009) New record of Scaphanocephalus expansus from the Canary Islands (Spain). Helminthologia 46:198-200

Gratzek JB (2010) Parasites associated with freshwater tropical fishes. In: Stoskopf MK (ed) Fish medicine, Vol 2. ART Sciences, Apex, NC, p 573-590

*Guindon S, Dufayard JF, Lefort V, Anisimova M, Hordijk W, Gascuel O (2010) New algorithms and methods to estimate maximum-likelihood phylogenies: assessing the performance of phyml 3.0. Syst Biol 59:307-321

* Hoffman GL, Wu LY, Kingscote AA (1953) Scaphanocephalus expansus (Crepl.), a trematode of the osprey, in North America. J Parasitol 39:568

Hutton RF (1964) A second list of parasites from marine and coastal animals of Florida. Trans Am Microsc Soc 83: 439-447

Inohuye Rivera RB (1995) Helmintofauna de cuatro especies de cabrillas del género Epinephelus Bloch, 1793 (Osteichthyes: Serranidae) en la costa sudoriental de Baja California Sur, México. MS thesis, Instituto Politécnico Nacional

Iwata K (1997) Scaphanocephalus larva from marine fishes of Iromote Island. Bull Inst Oceanic Res Devel Tokai Univ 18:43-50 (in Japanese with English Abstract)

Jägerskiöld (1904) Scaphanocephalus expansus (Crpl.), eine genital-napftragende Distomide. Results of the Swedish Zoological Expedition to Egypt and the White Nile 1901, Part I. KW Appelberg, Uppsala

* Justine JL, Leblanc P, Keller F, Lester RJG (2009) Turbellarian black spot disease in bluespine unicornfish Naso unicornis in New Caledonia, caused by the parasitic turbellarian Piscinquilinus sp. Dis Aquat Org 85:245-249

Kinsella JM, Cole RA, Forrester DJ, Roderick CL (1996) Helminth parasites of the osprey, Pandion haliaetus, in North America. J Helminthol Soc Wash 63:262-265

Kohl ZF, Calhoun DM, Elmer F, Peachey RJB and others (2019) Black-spot syndrome in Caribbean fishes linked to trematode parasite infection (Scaphanocephalus expansus). Coral Reefs 38:917-930

Kristmundsson A, Freeman MA (2014) Negative effects of Kudoa islandica n. sp. (Myxosporea: Kudoidae) on aquaculture and wild fisheries in Iceland. Int J Parasitol Parasites Wildl 3:135-146

Le Cren ED (1951) The length-weight relationship and seasonal cycle in gonad weight and condition in the perch (Perca fluviatilis). J Anim Ecol 20:201-219

Littlewood DTJ, Curini-Galletti M, Herniou EA (2000) The interrelationships of Proseriata (Platyhelminthes: Seriata) flatworms tested with molecules and morphology. Mol Phylogenet Evol 16:449-466

Marshell A, Mumby PJ (2015) The role of surgeonfish (Acanthuridae) in maintaining algal turf biomass on coral reefs. J Exp Mar Biol Ecol 473:152-160
McQueen A, Mackenzie K, Roberts RJ, Young H (1973) Studies on the skin of plaice (Pleuronectes platessa L.) III. The effect of temperature on the inflammatory response to the metacercariae of Cryptocotyle lingua (Creplin, 1825) (Digenea: Heterophyidae). J Fish Biol 5:241-247

Munro JL, Gaut VC, Thompson R, Reeson PH (1973) The spawning seasons of Caribbean reef fishes. J Fish Biol 5: 69-84

Nahhas FM (1993) Some Acanthocephala and Digenea of marine fish from Grand Cayman, Cayman Islands, British West Indies. J Helminthol Soc Wash 60:270-272

Nylander JAA, Ronquist F, Huelsenbeck JP, Nieves-Aldrey J (2004) Bayesian phylogenetic analysis of combined data. Syst Biol 53:47-67

* Olson PD, Cribb TH, Tkach VV, Bray RA, Littlewood DTJ (2003) Phylogeny and classification of the Digenea (Platyhelminthes: Trematoda). Int J Parasitol 33:733-755

Overstreet RM, Hawkins WE (2017) Diseases and mortalities of fishes and other animals in the Gulf of Mexico. In: Ward C (ed) Habitats and biota of the Gulf of Mexico: before the Deepwater Horizon oil spill. Springer, New York, NY, p 1589-1738

Pearson J (2008) Family Heterophyidae Leiper, 1909. In: Bray RA, Gibson DI, Jones A (eds) Keys to the Trematoda, Vol 3. CAB International and Natural History Museum, London, p 113-141

Poynton SL (2010) Parasites of cold-water marine fishes. In: Stoskopf MK (ed) Fish medicine, Vol 2. ART Sciences, Apex, NC, p 711-735

Poynton SL, Hoffman GL (2010) Parasites of temperate freshwater game fishes, including estuarine bait fishes. In: Stoskopf MK (ed) Fish medicine, Vol 2. ART Sciences, Apex, NC, p 300-308

R Core Team (2017) R: a language and environment for statistical computing. R Foundation for Statistical Computing, Vienna. www.R-project.org

Ricker WE (1975) Computation and interpretation of biological statistics of fish populations. Bull Fish Res Board Can No. 191

Robertson DR, Ackerman JL, Choat JH, Posada JM, Pitt J (2005) Ocean surgeonfish Acanthurus bahianus. I. The geography of demography. Mar Ecol Prog Ser 295:229-244

Ronquist F, Huelsenbeck JP (2003) Mrbayes 3: Bayesian phylogenetic inference under mixed models. Bioinformatics 19:1572-1574

Sikkel PC, Nemeth D, McCammon A, Williams EH Jr (2009) Habitat and species differences in prevalence and intensity of Neobenedenia melleni (Monogenea: Capsalidae) on sympatric Caribbean surgeonfishes (Acanthuridae). J Parasitol 95:63-68

Skinner RH (1978) Some external parasites of Florida fishes. Bull Mar Sci 28:590-595

* Stunkard HW (1930) The life history of Cryptocotyle lingua (Creplin), with notes on the physiology of the metacercariae. J Morphol 50:143-191

Tubangui MA (1933) Trematode parasites of Philippine vertebrates, VI. Descriptions of new species and classification. Philipp J Sci 52:167-197

Work TM, Aeby GS (2014) Skin pathology in Hawaiian goldring surgeonfish, Ctenochaetus strigosus (Bennett). J Fish Dis 37:357-362

Yoshihara K (1997) A fish body length measuring method using an underwater video camera in combination with laser discharge equipment. Fish Sci 63:676-680

Submitted: January 28, 2019; Accepted: August 29, 2019

Proofs received from author(s): November 25, 2019 